\title{
Homicidio alevoso, intervención delictiva y prescripción gradual. Comentario a la sentencia de la Corte de Apelaciones de Santiago en el caso «Villa Grimaldi» (rol 1734-2017)
}

\author{
Juan Pablo Mañalich R. \\ Universidad de Chile
}

\section{Introducción}

El 9 de abril de 2020, la Octava Sala de la Corte de Apelaciones de Santiago (en adelante, «la corte») pronunció una sentencia por la cual acogió parcialmente los recursos de apelación que habían sido interpuestos - junto con algunos recursos de casación en la forma, que fueron rechazados- por las defensas de algunos de los condenados por la sentencia definitiva dictada, el 21 de julio de 2017, por el ministro de fuero Leopoldo Llanos Sagristá. ${ }^{1}$ Como debería ser obvio, y a pesar de lo sugerido por múltiples medios de prensa, ninguna de las personas favorecidas por la decisión de la corte estaba cumpliendo alguna pena que hubiera sido impuesta por la sentencia de primera instancia, al no encontrarse esta firme. La mayor parte de esas personas, con todo, actualmente cumple una o más penas privativas de libertad impuestas en el marco de procesos diferentes, ya concluidos, en la cárcel de Punta Peuco. ${ }^{2}$

Argumentativamente, la parte considerativa del fallo de la corte admite ser descompuesta en cinco secciones. De ellas, las cuatro primeras involucran la aplicación de la legislación penal sustantiva, mientras que la quinta concierne a la cuantificación del daño moral cuya indemnización había sido solicitada a través del ejercicio de las correspondientes acciones civiles. En lo que sigue me ocuparé de evaluar los argumentos desplegados por la corte en esas primeras cuatro secciones, que respectiva-

1. En lo referido a los sobreseimientos definitivos dictados respecto de los imputados que murieron antes de que concluyera el proceso en primera instancia, la corte conoció en consulta.

2. Para una breve, pero informativa, reseña biográfica de cada uno de los 17 acusados que fueron condenados en primera instancia, véase Andrés Almeida y Nicolás Massai, «Estos son los 17 agentes de la Dina beneficiados por la Corte de Apelaciones de Santiago en el caso de la desaparición de 17 dirigentes comunistas en dictadura», Interferencia, 13 de abril de 2020, disponible en bit.ly/36doDy5. 
mente se ocupan de (i) la desestimación de la alevosía como calificante del homicidio imputado; (ii) la desestimación de la intervención de seis de los condenados como cómplices en el homicidio y en todos o algunos de los secuestros imputados; (iii) la desestimación de la intervención de dos de los condenados como autores del homicidio y de todos o algunos de los secuestros imputados; y (iv) el reconocimiento de la «media prescripción» como hiperatenuante a favor de los acusados cuyas condenas fueron confirmadas.

\section{La desestimación de la alevosía como calificante del homicidio}

Conociendo de las apelaciones deducidas contra la sentencia de primera instancia, la corte consideró, en primer lugar, la calificación que el tribunal a quo había dado al homicidio de Eduardo Canteros Prado - militante del Partido Comunista, al igual que las 16 víctimas de los secuestros conjuntamente imputados- como constitutivo de asesinato, al declarar que había sido perpetrado con alevosía en el sentido del número 1, circunstancia 1a , del artículo 391 del Código Penal. La corte desestimó la configuración de la calificante, sosteniendo que el ministro de fuero no había sustentado la caracterización del homicidio como alevoso, a propósito de lo cual la corte ofreció una muy problemática interpretación de la definición de «alevosía» plasmada en el número 1 del artículo 12 del Código Penal, que resulta rayana en la deshonestidad intelectual. En lo fundamental, se trata de una argumentación que reproduce una parte de las consideraciones con que la misma corte, en su sentencia del 19 de abril de 2018, ${ }^{3}$ relativa a crímenes perpetrados en el marco de la llamada "Operación Colombo» y cuya redacción también quedó en manos del ministro Juan Cristóbal Mera Muñoz, había desestimado que el homicidio de Ángel Gabriel Guerrero Carrillo —-militante del Movimiento de Izquierda Revolucionaria- hubiera sido perpetrado con alevosía (y, además, con premeditación). ${ }^{4}$

Para fundar las condenas referidas al homicidio en cuestión, el ministro de fuero tuvo por probado que Eduardo Canteros Prado,

48 años, constructor civil, [fue] detenido el 23 de julio de 1976 alrededor de las 21:40 horas en la vía pública, frente a su domicilio ubicado en calle Panamá 8807 de la comuna de La Florida, por agentes de la DINA que se movilizaban en tres automóviles, siendo trasladado hasta la "Villa Grimaldi". En el año 1990 sus restos fueron encontrados en el fundo Las Tórtolas de Colina, recinto que hasta 1980 perteneció al Ejército [considerando $2^{\circ}$, IV.c.].

\footnotetext{
3. Causa rol 260-2017.

4. Un pormenorizado comentario justificadamente crítico del fallo en cuestión se encuentra en Castillo (2018).
} 
Y declaró, además, que

[r]especto de Eduardo Canteros Prado, se estableció pericialmente que su muerte fue provocada por medios violentos, y atendidas las circunstancias que rodearon su detención y reclusión clandestina, se puede establecer que se debió a la acción de terceros [considerando $2^{\circ}$, párrafo final].

Sobre esta base, el ministro de fuero entendió que el homicidio imputado satisfacía la variante típica de asesinato por alevosía. Para rechazar esta calificación jurídica, la corte sostuvo que «[e]n ninguna parte de esta descripción el tribunal a quo describe una conducta alevosa» (considerando $5^{\circ}$ ). Pero del hecho de que el ministro de fuero no haya hecho uso de la palabra «alevosía» al fundamentar la correspondiente calificación del homicidio no se sigue que, en su sentencia, él no haya logrado sustentar la premisa fáctica de cuya justificación probatoria dependía la caracterización del homicidio en cuestión como alevoso. Más bien, debería ser obvio que el hecho de que el ministro Llanos no haya empleado la palabra «alevosía» resulta enteramente irrelevante a este respecto. Esto, porque la proposición de que ese homicidio fue alevoso está implicada por su afirmación de que el homicidio cuya perpetración él tuvo por probada estaría «previsto y sancionado en el artículo $391 \mathrm{~N}^{\circ} 1$, circunstancia primera, del Código Penal» (considerando $3^{\circ}$ ).

Con ello, y dado que la corte entendió que el problema radicaba exclusivamente en la calificación jurídica dada al homicidio por el tribunal a quo, la pregunta se reduce a si las circunstancias de hecho que el ministro de fuero tuvo por establecidas justificaban la calificación del homicidio como alevoso. Según consta en los pasajes ya citados de la sentencia de primera instancia, el ministro LLanos declaró probadas las siguientes proposiciones: (i) que Eduardo Canteros Prado fue detenido el 23 de julio de 1976 por agentes de la DINA, para ser trasladado al centro de tortura y exterminio Villa Grimaldi; (ii) que su muerte, acaecida a través de la aplicación de «medios violentos», quedó asociada a su detención y reclusión clandestina; y (iii) que su cadáver fue hallado, en 1990, en el terreno de un recinto que había pertenecido al Ejército de Chile hasta el año 1980. El fallo de primera instancia estimó suficiente la conjunción de estas tres proposiciones para establecer que la producción de la muerte de la víctima constituyó un homicidio perpetrado con alevosía.

En contra de la decisión de subsunción resultante de la inferencia así reconstruida, la corte esgrimió una peculiar interpretación, de índole subjetivista, de la expresión «alevosía». Para ello, hizo suya la usual consideración -obtenida a través de la puesta en relación de la formulación de la circunstancia $1^{\text {a }}$ del artículo 391, número 1, con la definición de la agravante prevista en el número 1 del artículo 12 del Código Penal- de que la alevosía conocería dos formas: la «traición» y el «obrar sobre seguro» (considerando $6^{\circ}$ ). Sobre esta base, y tras descartar que la primera de esas dos modalidades pudiera haberse visto realizada (considerando $7^{\circ}$ ), la corte sostuvo 
[q]ue es tarea más compleja resolver si el obrar de los autores fue "sobre seguro". Obrar de esta manera, siempre siguiendo a Novoa, implica tanto el poner asechanzas o preparar celadas, como el aprovechar circunstancias que hagan inevitable y cierto el mal que ha de sufrir el ofendido. Consecuentemente, para que exista alevosía y, específicamente, para entender que se obra sobre seguro, es necesario que las circunstancias que la constituyen sean buscadas de propósito por el agente, lo que no ha sucedido en la especie, en que no aparece de los hechos asentados en la sentencia que los autores de estos delitos hayan creado o procurado una situación de indefensión de las víctimas [considerando $8^{\circ}$..$^{5}$

A pesar de lo que sugiere el pasaje, esta última formulación es más próxima a la ofrecida por Etcheberry que a la ofrecida por Novoa. En efecto, aquel observa que, a pesar de que esta segunda forma que puede mostrar la alevosía «no parece requerir alguna subjetividad especial, sino la mera concurrencia de circunstancias que objetivamente aseguren, sea la ejecución del delito, sea la integridad del agente ante la eventual reacción de la víctima», habría que tener en cuenta que «si se reflexiona acerca de la razón de ser de la calificante, se advierte que el simple azar de circunstancias favorables no es motivo suficiente para considerar más grave un homicidio que otro» (Etcheberry, 1998a: 6o-61). De ahí que Etcheberry concluya que «la nota de reprobación moral surge cuando las condiciones de aseguramiento han sido especialmente buscadas o procuradas por el hechor, lo que revela también la existencia del ánimo alevoso» (Etcheberry, 1998a: 61).

Esta cita habría sido algo más apropiada para dar apoyo a la manera en que la corte pretendía zanjar el asunto:

Que si la naturaleza de la alevosía es subjetiva, como entiende casi toda la doctrina y la jurisprudencia, es preciso que el agente actúe con el propósito de aprovechar para la ejecución del ilícito la indefensión de la víctima, de manera que, por ejemplo, y así se ha fallado de antiguo, no necesariamente matar a un niño pequeño lleva consigo la alevosía y, consiguientemente, si en el orden de cosas existentes después del 11 de septiembre de 1973 la víctima, por sus circunstancias políticas, ya se encontraba en una situación de riesgo preexistente y el poder era ejercido por los cuerpos armados en forma absoluta, no puede entenderse que se obró sobre seguro, no puede argüirse que los agentes precisos de la muerte del señor Canteros Prado buscaron su situación de indefensión [considerando $9^{\circ}$ ].

Pero las apariencias engañan. Más allá de la osadía con la que la corte, sin aportar referencia bibliográfica alguna, se permitió afirmar que «casi toda la doctrina» haría suya una concepción subjetivista de la alevosía, ${ }^{6}$ esta ni siquiera es defendida por

5. Se han suprimido las negritas del original.

6. Una concepción auténticamente subjetivista de la calificante, aunque de una índole del todo hete- 
Etcheberry. Antes bien, y al contrastar la alevosía con la premeditación, él caracteriza esta última noción como un concepto «fundamentalmente subjetivo», frente a lo cual la alevosía sería "una circunstancia más bien objetiva» (Etcheberry, 1998a: 6162). Esto no obsta a que Etcheberry sostenga que la alevosía quedaría codefinida por un elemento subjetivo -que él denomina «ánimo alevoso»-, mas añadiendo que ese elemento subjetivo se vería satisfecho siempre que el o los perpetradores actúen «buscando o aprovechando circunstancias materiales que faciliten el éxito o procuren la impunidad» (Etcheberry, 1998a: 44).

Lo anterior contribuye a demostrar que, contra lo que sugiere el fallo de la corte, no hay sustento doctrinal para afirmar que para que se configure la calificante de la alevosía sería «necesario que las circunstancias que la constituyen sean buscadas de propósito por el agente». Antes bien, parece haber un consenso doctrinal en cuanto a que para ello sería suficiente un aprovechamiento de la situación objetiva de indefensión en la que ha de encontrarse la víctima, siendo necesario, según algunos autores, «que el aprovechamiento de ese estado se busque de propósito por el delincuente» (Politoff, Grisolía y Bustos, 1993: 117). ${ }^{7}$ Notablemente, una tesis cercana a esta última es favorecida por Novoa - cuya autoridad fuera invocada, infamemente, por la corte en apoyo de su propuesta interpretativa-, según quien la configuración de la alevosía solo exigiría "que el delincuente tenga conciencia de la indefensión de la víctima y de la falta de riesgo con el [sic] que opera y quiera obrar aprovechando esas circunstancias favorables para él», de lo cual se seguiría que actúa con alevosía quien «sin ánimo preordenado aprovecha un estado de absoluta imposibilidad defensiva de parte de su víctima para consumar el ataque» (Novoa, 2005: 44).

Así podemos concluir que, en contra de lo sostenido por la corte, la exigencia de que la generación de las circunstancias constitutivas de la situación de indefensión de la víctima sea intencionalmente perseguida por el o los perpetradores del homicidio respectivo carece de apoyo doctrinal. Antes bien, y en un caso como el aquí considerado, tendría que bastar con que los perpetradores se hayan decidido a ejecutar la acción letal contra la víctima a sabiendas de que esta se encontraba en una situación de indefensión, de la cual, en tal medida, ellos se habrán aprovechado «intencionalmente». ${ }^{8}$

Esto debería ser suficiente para reconocer la auténtica falacia en la que incurrió la

rogénea frente a aquella asumida por la corte, fue defendida por Rivacoba, según quien la esencia de la alevosía consistiría en la manifestación de «una personalidad desleal y cobarde, que disimula u oculta sus intenciones y procura evitarse riesgos» (De Rivacoba y Rivacoba, 1981: 240). Frente a la objeción de que esto sería más bien propio de un modelo de derecho penal de autor, Rivacoba explícitamente admitía que su concepción se centraría en «aquel aspecto de su personalidad [la del hechor], que se transparenta en su acto» (De Rivacoba y Rivacoba, 1981: 241).

7. Véase también Garrido (2010: 58-59).

8. Sobre ello, véase Castillo (2018: 699-700). 
corte al presentar su argumento, pretendidamente decisivo, para rechazar la calificación del homicidio como asesinato, plasmado en un pasaje que conviene reproducir in extenso:

Se ha dicho sobre este particular que los elementos precisos para la estimación de esta calificante han de referirse a los medios, modos o formas de ejecutar el hecho, tendiendo a su aseguramiento y a la vez a la impunidad del agente que lo realiza, revelando una perversidad de su propósito. No se trata, en el caso sub lite, de un grupo de militares que procedieron por sí y ante sí deteniendo arbitrariamente a una persona y matándola una vez privada de libertad, se trata de un proceso de política de Estado fijado por el nuevo orden de cosas imperante a partir de los sucesos del 11 de septiembre de 1973, en que las Fuerzas Armadas y de Orden derrocaron el gobierno constituido y comenzaron una persecución de los militantes y simpatizantes del gobierno anterior, de suerte que los agentes que dieron muerte a las víctimas de este proceso no buscaron personalmente la situación de superioridad armada que les daba su condición de militares, sino que ello iba de suyo en un régimen controlado precisamente por las Fuerzas Armadas y de Orden desde más de dos años antes de sucedidos los hechos. Razonar en contrario equivale a concluir que todo homicidio cometido por los funcionarios de la Administración a partir del 11 de septiembre de 1973, por el solo hecho de ser miembros de los organismos armados del Estado, es alevoso, idea que lleva al reprochable derecho penal de autor, vale decir, se juzgaría a los autores por su condición de militares en un régimen político autoritario y no por sus actos; no parece ser entonces una doctrina que se adecue a las exigencias del Derecho Penal liberal el ver siempre un obrar sobre seguro en delitos de esta índole [considerando $8^{\circ}$.

De este modo, según la corte, el hecho de «que los agentes que dieron muerte a las víctimas de este proceso no buscaron personalmente la situación de superioridad armada que les daba su condición de militares» proveería, supuestamente, una razón para desestimar que el homicidio de Eduardo Canteros Prado haya sido perpetrado alevosamente. Sin embargo, esto último solo se dejaría afirmar, siquiera prima facie, si en la modalidad del obrar «sobre seguro» la concurrencia de alevosía en efecto requiriera que los perpetradores hubieran buscado producir la situación de indefensión de la víctima, que aquí sería correlativa a la «situación de superioridad armada» en la que se encontraban los perpetradores. Ya se ha mostrado que esa premisa es errada.

Pero a ello se añade que, al mismo tiempo, la corte precisamente pretendiera identificar la situación de superioridad correlativa a la situación de indefensión de la víctima con aquella que a los perpetradores brindaba «su condición de militares». Esta premisa parece ser la que sustenta la maniobra de reducción al absurdo con la que la corte se permitió jugar, al observar que calificar el homicidio de Eduardo Canteros Prado como alevoso equivaldría «a concluir que todo homicidio cometido por los funcionarios de la Administración a partir del 11 de septiembre de 1973, por el sólo 
[sic] hecho de ser miembros de los organismos armados del Estado, es alevoso». La falacia así desplegada debería ser fácil de advertir: la conclusión sugerida ad absurdum por la corte solo podría seguirse si la indefensión en la que se encontraba la víctima frente a sus captores no hubiera sido más que el correlato del estatus formal de estos como «funcionarios de la administración», en vez del correlato de las posibilidades de acción que a estos confería su pertenencia a una organización como la DINA, cuyas operaciones eran promovidas y supervigiladas por el mismo régimen dictatorial que la había creado un par de años antes. ${ }^{9}$

Esto deviene en una argumentación que solo cabe caracterizar como siniestra, si se repara en cómo la corte pretendía rematar sus disquisiciones a este respecto, a saber: sugiriendo que la calificación del homicidio en cuestión como alevoso supondría validar un modelo de «derecho penal de autor» que repugnaría al paradigma de un «derecho penal liberal», como si el factor decisivo a favor de esa calificación correspondiera al estatus de los condenados, a la época de los acontecimientos, como miembros de las Fuerzas Armadas y de Orden. Lo siniestro de esta sugerencia tendría que resultar patente si recordamos que la única evocación de algo parecido a un modelo de derecho penal de autor que sería aquí pertinente concierne al modo en el cual el aparato dictatorial pretendió legitimar su política de persecución y exterminio etiquetando a sus víctimas como «terroristas» $\mathrm{O}$ «subversivos». ${ }^{10}$

\section{La desestimación de la intervención en los delitos de homicidio y de secuestro a título de complicidad}

Las dos secciones siguientes de la parte considerativa del fallo de la corte se refieren a la intervención de varios de los acusados en todos o algunos de los hechos punibles comprendidos en las acusaciones. En lo fundamental, las consideraciones esgrimidas por la corte para rechazar las correspondientes imputaciones descansan en que la responsabilidad atribuida a cada una de esas personas habría tenido, como único fundamento, su condición de agentes de la DINA.

Tratándose de seis de los acusados - Bitterlich Jaramillo, Pacheco Fernández, Torrejón Gatica, Altamirano Sanhueza, López Inostroza y Alfaro Mundaca-, la corte volvió a invocar la etiqueta del «derecho penal de autor» para desacreditar la manera en que el tribunal a quo había fundamentado las respectivas imputaciones a título de

9. Acerca de la vacilación mostrada por la Corte Suprema en la sentencia recaída en el llamado «caso Prats» para caracterizar a la DINA como una asociación ilícita institucionalmente configurada, véase Couso (2019: 313 y ss.). Para un análisis detallado del problema, véase también Mañalich (2018a: 305 y ss.; 315 y ss.).

10. Sobre la estrategia de "proyección-negación» implementada por el régimen dictatorial a través de la puesta en vigor de Ley 18.314, «que determina delitos terroristas y establece su penalidad», véase Mañalich (2015: 156 y ss.). 
complicidad. La corte ejemplificó el problema en referencia inmediata a la situación de uno de los condenados, con respecto a quien el fallo de primera instancia habría establecido que

aun cuando no se acreditó que ejecutó actos propios de la autoría de ninguno de los delitos de esta causa, [...] habría cooperado por ser un agente de la DINA, conclusión que es inaceptable, desde luego, y que nuevamente lleva al criticado "derecho penal de auto", en que se castiga por tener una determinada calidad y no por haber desplegado alguna conducta que pueda calificarse de delictiva [considerando $10^{\circ}$ ].

Sin embargo, esta aparente reformulación abreviada entraña una tergiversación de lo efectivamente declarado en la sentencia apelada. En el considerando $56^{\circ}$ de esta, al cual hace referencia el correspondiente considerando de la sentencia de la corte, el ministro de fuero no identificó en lo absoluto la base para atribuir responsabilidad al respectivo acusado con su mera condición de agente de la DINA, sino más bien con el hecho de tratarse de uno de los agentes que, a la época de los acontecimientos, se desempeñaban en los cuarteles donde estuvieron privadas de libertad las víctimas de los delitos en cuestión. Por la vía de no reproducir adecuadamente el fundamento esgrimido por el tribunal a quo, la corte lo redujo a una caricatura que oscurece el hecho de que la consideración vertida en la sentencia de primera instancia pretendía servir de base para la construcción de una inferencia probatoria - constitutiva de una "presunción judicial»- capaz de sustentar la afirmación de que el acusado en cuestión colaboró con la perpetración de los secuestros «por actos anteriores o simultáneos», según lo exige el artículo 16 del Código Penal.

Pero a lo anterior se añade que, aparentemente para reforzar su argumento desestimatorio de la intervención de los referidos acusados como cómplices en los crímenes correspondientes, la corte llegó a sostener lo siguiente:

En el caso sub judice, como en otros tantos de la misma naturaleza, a los que en algunas oportunidades se les dice "cómplices" o en otras "encubridores", fueron funcionarios de un aparato estatal de inteligencia encargado de reprimir a los opositores al nuevo orden político surgido a contar de los sucesos del 11 de septiembre de 1973, es decir, se trataba de una política de Estado en la que los referidos encausados [...] no tuvieron responsabilidad alguna, simplemente se los destinó, como miembros de las fuerzas armadas o de orden, a la DINA y cumplieron allí diversas tareas, que van desde detener personas, hacer guardias en el interior o en el exterior de los recintos de detención u otras menores [considerando $11^{\circ}$ ].

Es notable que exactamente la misma consideración, relativa a que los acusados habrían estado operando en el marco de una política de Estado implementada a partir del 11 de septiembre de 1973, apareciera en la argumentación ofrecida por la corte para desestimar el carácter alevoso del homicidio imputado a algunos de esos 
mismos acusados. La ubicuidad de esa consideración vuelve plausible la conjetura de que la corte parece haber asumido que el hecho de que los acusados se hubieran desempeñado como miembros de una organización diseñada e instituida para la implementación de esa política de Estado proveería una razón, de alcance más bien general, para desconocer la posible significación criminal del comportamiento desplegado por ellos en cuanto agentes de esa organización.

Mas esto pasa por alto, de un modo que roza el cinismo, que la política de Estado en cuestión se vio sustentada por la actividad criminal desplegada por los agentes de los aparatos represivos. ${ }^{11}$ Es obvio que, como lo observara la corte en el mismo considerando $11^{\circ}$, en el caso al cual se refería su sentencia los comportamientos delictivamente relevantes no pueden ser identificados con la mera integración de la DINA por parte de los acusados, por cuanto lo imputado a cada uno de ellos no era un correspondiente delito de asociación ilícita. Pero de esto ciertamente no se sigue que el hecho de que a la época de los acontecimientos los acusados se hayan desempeñado como agentes de la DINA en los cuarteles donde, según pudo ser establecido por el tribunal a quo, estuvieron detenidas las víctimas de los delitos en cuestión, carezca de relevancia probatoria para fundamentar una atribución de responsabilidad por esos delitos a título de complicidad.

\section{La desestimación de la intervención en los delitos de homicidio y de secuestro a título de autoría}

Una objeción similar puede dirigirse contra el argumento a través del cual la corte buscó desestimar la imputación a título de autoría de todos o algunos de los secuestros, respectivamente, así como del homicidio de Eduardo Canteros Prado, a los acusados Espinoza Bravo y Wenderoth Pozo. Esto, porque esa desestimación descansa en una consideración del todo similar a la esgrimida por la corte para desestimar las ya referidas imputaciones a título de complicidad. En efecto, y con respecto a Espinoza Bravo, la corte sostuvo que

no hay evidencia de que haya liderado ninguna brigada que operara en Villa Grimaldi ni menos la agrupación Delfín durante el año 1976, que es lo que importa para estos efectos. Fue director de Villa Grimaldi desde noviembre de 1974 y hasta mediados de febrero de 1975, desempeñándose en 1976 en el cuartel general de la DINA. El hecho de que las brigadas hayan dependido administrativamente del Director de Operaciones, que era precisamente Pedro Espinoza Bravo, no importa necesariamente que éste haya desplegado alguna conducta de aquellas señaladas en el artículo 15 del Código Penal, según lo consignado precedentemente. En definitiva, el alto cargo de Espinoza en la DINA no lo vincula ni lo puede vincular con los hechos

11. Sobre esto, véase Mañalich (2010: 23 y ss.). 
exactos que en esta causa se conocen, que corresponden al secuestro y posterior desaparición de 16 personas, y secuestro y homicidio de una $17^{\mathrm{a}}$ víctima, hechos todos ocurridos en 1976 y llevados a cabo por la agrupación Delfín [considerando 16º.$^{12}$

La estrategia argumentativa es suficientemente clara: el hecho de que el acusado haya efectivamente ocupado, a la época de los acontecimientos, tan «alto cargo» en la estructura organizacional de la DINA no bastaría para vincularlo con los múltiples delitos perpetrados en cuarteles de la DINA, en los cuales se desempeñaban agentes jerárquicamente sometidos a la «autoridad» de aquel.

No deja de ser notable que la descripción que la corte ofreciera de esta última relación de subordinación como una de «dependencia administrativa» logre evocar la caracterización que, según la célebre observación de Hannah Arendt en su retrato de la «banalidad del mal», Adolf Eichmann hiciera de sí mismo como un burócrata que cumplía el rol que le cabía en un engranaje burocrático cuyo funcionamiento él no controlaba. ${ }^{13}$ Más allá de esto, no puede ser soslayado el vocabulario con el cual la corte intentó desconocer la vinculación, afirmada por la sentencia de primera instancia, entre Espinoza Bravo y los crímenes perpetrados por sus subordinados. En el fragmento del considerando recién citado, la corte dice que en el hecho de que el acusado hubiera ocupado la posición de Director de Operaciones de la DINA «no importa necesariamente que éste haya desplegado alguna conducta de aquellas señaladas en el artículo 15 del Código Penal», agregando que "el alto cargo de Espinoza en la DINA no lo vincula ni lo puede vincular con los hechos exactos que en esta causa se conocen». ${ }^{14}$

Por la vía de echar mano a semejante terminología modal - «necesariamente», «no (lo) puede»-, la corte volvió a tergiversar el razonamiento desplegado por el tribunal a quo de un modo que confirma la sospecha de que la corte ni siquiera fue capaz de diferenciar el razonamiento subsuntivo requerido por la aplicación de las correspondientes reglas sustantivas, por un lado, del razonamiento inductivo que es propio de la construcción de inferencias probatorias, por otro. Pues entre otras cosas, en la sentencia de primera instancia se afirma, con base en la declaración prestada por uno de los otros acusados en el marco del mismo proceso, que Espinoza Bravo

[e]n marzo de 1976 es nombrado comandante de la División de Inteligencia Metropolitana con sede en Villa Grimaldi, y que los detenidos estaban a cargo de las brigadas, cuyos jefes dependían directamente del Director de Operaciones, que era Pedro Espinoza, y este a su vez dependía del coronel Manuel Contreras; y que cuando los detenidos llegaban a Villa Grimaldi, el jefe de la Brigada le informaba directa-

12. Se han suprimido las negritas del original.

13. Al respecto, véase Arendt (1964: 21 y ss.; 36 y ss. 135 y ss.).

14. Las cursivas han sido añadidas. 
mente al deponente, quien a su vez informaba verbalmente a Pedro Espinoza en su calidad de Director de Operaciones [considerando $7^{\circ}, \mathrm{b}$ ].

A esto se añadía, como un antecedente probatorio aportado por un informe evacuado por el Departamento V de la Policía de Investigaciones, que Espinoza Bravo

regresó al país en octubre de 1975, poniendo en marcha la Subdirección de Operaciones, asumiendo el mando de ella el 2 de marzo de 1976, transformándose al poco tiempo en Dirección de Operaciones, teniendo por misión además de la Central de Operaciones del Cuartel General de la DINA, asumir el mando y coordinación de las actividades de la BIM y de las BIR [considerando $\left.7^{\circ}, \mathrm{h}\right] . .^{15}$

El ministro de fuero agregó entonces que Espinoza Bravo

coordinó el trabajo dirigido al Partido Comunista, incorporando personal de inteligencia de la FACH y de Carabineros; en tanto que el Comando Conjunto se enfocaría en las Juventudes Comunistas (JJ.CC.), división que se acordó en enero de 1976. Señala además que, de acuerdo con la investigación, en el año 1976 se fusionaron las Brigadas Lautaro y Purén, y comenzaron a detener a militantes comunistas, utilizando como recintos de reclusión los cuarteles Venecia, Villa Grimaldi y Simón Bolívar [considerando $7^{\circ}, \mathrm{h}$.

Con esto, tendría que ser claro que la sentencia de primera instancia no sugiere en lo absoluto que constatar que el acusado había ocupado un «alto cargo» en la DINA sea condición suficiente para atribuirle responsabilidad como autor de los delitos inmediatamente perpetrados por los agentes de la DINA en los cuarteles respectivos. Se trata, antes bien, de que un conjunto de antecedentes concernientes a las precisas circunstancias en las que fueron perpetrados los crímenes en cuestión, así como al grado de supervisión que como Director de Operaciones de la DINA Espinoza Bravo ejercía sobre los perpetradores, así como al conocimiento de las formas de operación que se desarrollaban en esos cuarteles al haber estado él previamente a cargo de uno de ellos - Villa Grimaldi-, proveería suficiente apoyo inductivo a la correspondiente hipótesis acusatoria.

La misma observación vale, mutatis mutandis, con respecto a la manera en que la corte negó que a Wenderoth Pozo fuera atribuible una intervención a título de autor en los delitos por los cuales él había sido condenado en primera instancia. Al respecto, la corte sostuvo que

el hecho que [sic] Wenderoth Pozo haya pertenecido a la DINA y que haya alcan-

15. De acuerdo con lo que cabría caracterizar como el organigrama de la DINA, los acrónimos «BIM» $\mathrm{y}$ «BIR» significan, respectivamente, «Brigada de Inteligencia Metropolitana» $\mathrm{y}$ «Brigada de Inteligencia Regional». Al respecto, véase Salazar (2011: 112-113). 
zado a partir de diciembre de 1975 el cargo de jefe de la Subdirección de Inteligencia Interior no lo vincula con ninguno de los delitos que se conocen en estos autos, todos cometidos en 1976 por la denominada agrupación Delfín, con miras de atacar a los militantes del Partido Comunista, sin que se tengan noticias de que este acusado haya pertenecido a dicha agrupación o de que les haya dado las órdenes necesarias para que se secuestrara a las víctimas ya mencionadas [considerando $17^{\circ}$ ].

Así la corte volvía a tergiversar lo efectivamente consignado por el ministro de fuero en su fallo, quien más bien había concluido que

los antecedentes probatorios antes reseñados constituyen un conjunto de indicios que permiten presumir que el encausado Wenderoth Pozo no solo cumplía labores de análisis de la información entregada por los grupos operativos, y logísticas, como afirma; sino que a la época de la detención de las víctimas antes referidas era uno de los oficiales de más alta graduación de la DINA, a cargo de la Subdirección de Inteligencia Interior de la Dirección de Operaciones, la cual tenía tuición sobre la Brigada de Inteligencia Metropolitana; y que los grupos operativos, que dependían de esta, tenían por objetivo detener militantes de partidos de izquierda (como el Partido Comunista, al cual pertenecían dichas víctimas), sin orden judicial alguna, con fines de represión política, y trasladarlos hasta los recintos de detención de la DINA (como "Villa Grimaldi" y "Simón Bolívar"), en donde procedían a interrogarlas bajo apremios o torturas y eventualmente darles muerte (como aconteció con Eduardo Canteros Prado); encontrándose los ofendidos ya señalados entre las personas aprehendidas por los grupos operativos antes indicados, y que fueron mantenidos ilegalmente privados de libertad y torturados en esos recintos [considerando $20^{\circ}$ ].

Si alguna debilidad argumentativa exhibe, prima facie al menos, la sentencia de primera instancia en lo tocante a la fundamentación de la responsabilidad atribuida a Espinoza Bravo y Wenderoth Pozo, esa debilidad radica en la falta de precisión con la que en el fallo es identificada la específica forma de autoría asociada a esa responsabilidad. En referencia al primero de los dos acusados, el fallo apelado le atribuyó la «calidad de autor, a lo menos, de la hipótesis del inciso $2^{\circ}$ del Art. 141 del Código Penal», al haber proporcionado «el lugar para la ejecución de los delitos de secuestro», para entonces agregar que

[i]gualmente, indujo directamente a otros para la ejecución de los ilícitos (incluido el homicidio calificado) al tener uno de los cargos de mayor jerarquía y mando dentro de la organización, ante el cual rendían cuenta los demás oficiales subalternos; y, con todo, no puede sino concluirse, a base de los elementos de juicio reunidos en el proceso, que se encontraba concertado con aquellos para la ejecución de los delitos, facilitando los medios para que se llevaran a efecto [considerando $8^{\circ}$ ].

En este último pasaje, el tribunal a quo declara satisfechos tanto los presupuestos 
de una inducción, que el número 2 del artículo 15 equipara - a lo menos en cuanto a su penalidad - a la autoría, como los presupuestos de una coautoría «no-ejecutiva», prevista en el número 3 del mismo artículo. ${ }^{16}$ Esto no es en absoluto problemático, en la medida en que se reconozca que los presupuestos de una y otra forma de responsabilidad no son recíprocamente excluyentes. Pero no deja de tener importancia atender a la razón de que en último término llevó al ministro de fuero a privilegiar la invocación del número 2 del artículo 15 para identificar el título de responsabilidad fundante de las múltiples condenas pronunciadas contra Espinoza Bravo:

Debe considerarse, por último, que en el caso de crímenes de lesa humanidad, la jurisprudencia de los Tribunales Internacionales ha considerado que tratándose de estructuras jerarquizadas - como las militares-, existe, junto al autor ejecutor, un autor particular de la infracción internacional, que es el superior jerárquico, forma de participación que emana de las órdenes que dio, estando comprometida su responsabilidad en calidad de superior jerárquico, y siempre que forme parte de la cadena de mando. Así lo ha establecido la jurisprudencia del Tribunal Penal Internacional para Ruanda y del Tribunal Penal Internacional para la Ex Yugoslavia, que ha señalado que los elementos constitutivos para la responsabilidad del superior provienen del Art. 86-2 del Protocolo Adicional a las Convenciones de Ginebra, además de otros instrumentos internacionales, siendo estos elementos: 1. La existencia de un vínculo de subordinación entre el ejecutor y el superior jerárquico; 2. El conocimiento o el conocimiento implícito del superior de que el crimen iba a ser cometido o era cometido o se había cometido; 3. La omisión por parte del superior de tomar las medidas necesarias y razonables para impedir la perpetración del crimen o para castigar al autor [considerando $\left.8^{\circ}\right] . .^{17}$

De esta manera, el ministro de fuero buscaba dar cuenta de que el carácter de crímenes de lesa humanidad atribuible, con arreglo al derecho internacional, a los hechos punibles a los cuales se referían las acusaciones alcanzaría a tener un impacto, asimismo en conformidad con el derecho internacional, en las estructuras de imputación pertinentes para fundar la responsabilidad de quienes ocupaban posiciones de mando o autoridad en organizaciones jerarquizadas que sirvieron como plataformas para la perpetración de esos mismos hechos punibles. No obstante, y tal como su sentencia lo hiciera explícito, esto no tendría que ser tomado en el sentido de que esa apelación a los correspondientes estándares de derecho internacional sea la que fun-

16. Para la correspondiente propuesta de interpretación del artículo 15 del Código Penal, véase Mañalich (2011: 285-286).

17. En ese mismo contexto, el fallo de primera instancia contiene una referencia al «auto de procesamiento dictado por la Corte de Apelaciones de París, Tribunal de Gran Instancia de París, magistrado Sophie Clement, No de instrucción 275/o1/88, sobre secuestros con uso de torturas, víctimas Alphonse Chanfreau y otros». 
de la imputación múltiple dirigida contra Espinoza Bravo. Antes bien, el sentido de esa apelación es el de una referencia ilustrativa, orientada a proveer sustento adicional a la aseveración de que «la participación del imputado Espinoza Bravo, respecto de los delitos de secuestro simple y de homicidio calificado de la víctima de autos, se encuentra bajo la hipótesis de autoría del numeral $2^{\circ}$ del Art. 15 del Código Penal» (considerando $8^{\circ}$ ).

Desde este mismo punto de vista resulta sorprendente que, para desvirtuar el mérito de las múltiples condenas pronunciadas contra Espinoza Bravo como autor de los delitos respectivos, la corte se permitiera introducir una referencia a la llamada «teoría del dominio del hecho», aunque sin ofrecer apoyo bibliográfico alguno, en los siguientes términos:

Una de las teorías más aceptadas en el derecho penal actual, con respecto a la autoría, es la del dominio del hecho, según la cual tiene el dominio del hecho y consiguientemente es autor quien, en razón de una decisión de su voluntad, dirige consciente y finalísticamente el acontecer causal a la realización del resultado típico, esto es, cualquiera que tiene en sus manos el desarrollo de la conducta que el legislador ha tipificado puede interrumpir o detener la realización de dicha figura. No ve esta Corte evidencia que permita sostener que Espinoza y Wenderoth dieron alguna orden en relación con las diecisiete víctimas de autos, que haya [sic] participado materialmente en la detención, desaparición o muerte de alguna de ellas, de modo que no se les puede atribuir el dominio del hecho y que ellos hayan podido interrumpir o abortar el desarrollo de los actos típicos [considerando $18^{\circ}$ ].

No deja de ser llamativo el grado de fragmentariedad con el que la corte reseñara en qué consistiría el criterio del dominio del hecho. La corte prescinde enteramente de mencionar que, junto al «dominio de la acción» (fundante de autoría directa), al «dominio de la voluntad» (fundante de autoría mediata) y al «dominio funcional» (fundante de coautoría), que en su sentencia no alcanzan a ser siquiera aproximativamente diferenciados, los partidarios de la teoría del dominio del hechor reconocen, más recientemente, una forma autónoma de «dominio de organización». Esta se distinguiría por hacer posible la atribución de responsabilidad, a título de autoría mediata, a quienes ocupan posiciones de relativa superioridad al interior de algún «aparato organizado de poder», ${ }^{18} \mathrm{y}$ como tal ha llegado a ser jurisprudencialmente reconocida, siquiera tendencialmente, en casos muy de cerca emparentados con el caso al cual se refería la sentencia aquí analizada. ${ }^{19}$

18. Para una muy representativa visión de conjunto, véase los trabajos reunidos en Ambos y Meini (2010), inmediatamente referidos a la sentencia pronunciada por el Tribunal Supremo del Perú en el llamado «caso Fujimori».

19. Al respecto, véase Hernández (2011: 393 y ss.). 
Más allá de la valoración dogmática que merezca esta última construcción, ${ }^{20}$ tendría que ser claro que, si hubiera sido mínimamente rigurosa en su invocación de la teoría del dominio del hecho, la corte habría podido advertir que esa construcción doctrinal proveía apoyo ulterior a la declaración de que Espinoza Bravo y Wenderoth Pozo tendrían responsabilidad en los crímenes que les fueran respectivamente imputados con base en el número 2 del artículo 15, si esta disposición es interpretada como abarcadora de una autoría mediata por dominio de organización. ${ }^{21}$

Por supuesto, es concebible que la corte hubiera podido rechazar una solución como la recién apuntada (simplemente por mor del argumento). Pero ello no la eximía de considerar seriamente, y sin caricaturas, las inferencias probatorias plasmadas en el fallo de primera instancia para sustentar una atribución de autoría a uno y otro acusado, y esto quiere decir: también en cuanto a la posible configuración de una coautoría «no-ejecutiva», en los términos del número 3 del artículo 15 del Código Penal.

En cuanto a esto último, la corte se contentó con sostener que «no ha sido Espinoza Bravo ni Wenderoth Pozo los que han facilitado los medios de ejecución ni hay prueba de que hayan presenciado los delitos sin tomar parte directa en ellos» (considerando $18^{\circ}$ ). Ello manifiesta una renuncia a valorar la inferencia probatoria a través de la cual el tribunal a quo pretendía tener por corroborada la existencia de una intervención de uno y otro acusado en cada uno de los delitos que respectivamente se les imputaban. Esto, en consideración a que las posiciones que, a la época de perpetración de esos delitos, ellos ocupaban los habrían llevado a ostentar un grado significante de control, inmediato o mediato, sobre lo que ocurría en los cuarteles en los que operaban los integrantes de las correspondientes brigadas de la DINA. Y no parece en absoluto aventurado sostener que, por haber supervigilado el funcionamiento de los respectivos centros de tortura y exterminio, de ambos pueda decirse que facilitaron, a lo menos parte, los medios para la perpetración de los delitos respectivos. En la medida en que esto último haya logrado ser reconducido, sobre la base de un razonamiento presuntivo como el que es posible detectar en el fallo del ministro de fuero, a un concierto previo que hubiera involucrado a uno y otro acusado con los perpetradores directos, entonces a cada uno de esos dos acusados cabría atribuir una intervención constitutiva de coautoría en los crímenes respectivos, en los términos del artículo 15, número 3, del Código Penal.

20. Críticamente al respecto, véase Reyes (2018: 114 y ss.; 126 y ss.). Para el esbozo de un argumento favorable a fundamentar la autoría del así llamado «autor del escritorio», en los casos aquí relevantes, a través de la construcción de una coautoría vertical, véase Mañalich (2017: 45-46).

21. Para el esbozo de una refutación de esa interpretación, empero, véase Mañalich (2011: 285, nota 20). 


\section{El reconocimiento de la «media prescripción»}

La última sección de la parte considerativa del fallo de la corte, en lo tocante a la aplicación de la legislación penal sustantiva, se corresponde con el argumento mediante el cual ella tuvo por configurada la hiperatenuante prevista en el artículo 103 del Código Penal, popularmente etiquetada como «media prescripción», a favor de todos los acusados cuyas condenas no llegaron a ser revertidas in toto por la sentencia de segunda instancia.

Son conocidas las objeciones que cabe dirigir contra la tesis, identificada con la llamada «doctrina Dolmetsch», según la cual el carácter imprescriptible de la acción penal referida a delitos que según el derecho internacional tienen el estatus de crímenes de lesa humanidad no obstaría a la aplicabilidad de la regla del artículo 103. Esto, porque la diversa «naturaleza jurídica» que exhibiría la prescripción de la acción penal en cuanto «causa de extinción de la responsabilidad, por un lado, frente a la prescripción gradual como mera atenuante de eficacia extraordinaria, por otro, carece de relevancia para zanjar la pregunta de si la prescripción gradual puede operar allí donde la respectiva acción penal es imprescriptible». ${ }^{22}$

La falacia sobre la que descansa la doctrina Dolmetsch es fácil de advertir en el pasaje en el cual, en el fallo aquí considerado, la corte le rindió tributo:

[E]sta institución es una mera circunstancia atenuante, de modo que no puede equipararse, en su esencia, con la prescripción de la acción penal, que extingue la responsabilidad penal. De allí que todo lo que pueda argüirse para la no declaración de la prescripción en virtud de la naturaleza del delito de autos no es aplicable a una atenuante que solo tiene en común con la prescripción el transcurso del tiempo [considerando $21^{\circ}$ ].

La trampa en la que se incurre cuando se argumenta de esta manera es fácil de develar: lo que tienen en común una y otra «institución» es algo más que el «transcurso del tiempo». ${ }^{23}$ Considérese lo que dice el artículo 103 del Código Penal:

Si el responsable se presentare o fuere habido antes de completar el tiempo de la prescripción de la acción penal o de la pena, pero habiendo ya trascurrido la mitad del que se exige, en sus respectivos casos, para tales prescripciones, el tribunal deberá considerar el hecho como revestido de dos o más circunstancias atenuantes muy calificadas y de ninguna agravante, y aplicar las reglas de los arts. 65, 66, 67 y 68, sea en la imposición de la pena, sea para disminuir la ya impuesta.

22. Al respecto, véase Mañalich (2010: 233-234), con referencias ulteriores; también Mañalich (2018b: 78-79).

23. Esto queda de manifiesto en el hecho de que, como acertadamente apunta Castillo (2018: 701), «tanto a la plena como a la media prescripción les son igualmente aplicables las normas relativas a la suspensión e interrupción del plazo que corre». 
De acuerdo con el solo tenor de la disposición legal, el presupuesto para que se entiendan configuradas las dos o más atenuantes muy calificadas se identifica con que haya «transcurrido la mitad [del tiempo] que se exige [...] para tales prescripciones». Esto a su vez presupone, en lo que aquí interesa, que en relación con el hecho punible del que se trate esté previsto un lapso cuyo transcurso lleve a la prescripción de la acción penal. Pero si, en conformidad con los correspondientes estándares del derecho internacional, se entiende - como lo viene haciendo hace más de tres lustros la Corte Suprema- que tratándose de hechos punibles constitutivos de crímenes de lesa humanidad la acción penal es imprescriptible, entonces de esto se sigue que la regulación aplicable no prevé lapso alguno cuyo transcurso pudiera dar lugar a una prescripción de la acción penal. Esto tendría que ser suficiente para concluir que, en relación con esos mismos hechos punibles, la regla del artículo 103 deviene, literalmente, inaplicable.

En su fallo, la corte perpetúa la aberración jurídica — que en rigor superviene a una aberración lógica - en la que consiste la doctrina Dolmetsch. Sin embargo, la corte no se detuvo ahí, sino que además nos obsequió un auténtico oxímoron que raya en lo macabro, al declarar que

el transcurrir del tiempo nunca es indiferente al derecho y ciertamente tampoco al derecho penal, incluso en ilícitos de esta naturaleza, pues jamás será lo mismo juzgar un hecho ocurrido en el presente a unos sucedidos hace más de cuarenta y cuatro años, como los de la especie [considerando $\left.21^{\circ}\right] .{ }^{24}$

Al afirmar esto último, la corte no hizo más que borrar con el codo lo que acababa de escribir con la mano. Pues su previa admisión de que la acción penal es imprescriptible en relación con hechos punibles constitutivos de crímenes de lesa humanidad no puede sino significar que, a lo menos en este ámbito, «el transcurrir del tiempo» sí es «indiferente al derecho». Más allá de esto, sin embargo, lo que resulta auténticamente intolerable es que, en el pasaje recién citado, la corte termine confesando que esa admisión ha tenido lugar, de su parte, a regañadientes. Si de ella dependiera, la corte aparentemente estaría disponible para dejar caer el manto del olvido sobre los crímenes perpetrados por los agentes de la DINA.

\section{Referencias}

Амвоs, Kai e Iván Meini (2010). La autoría mediata. El caso Fujimori. Lima: Ara. Arendt, Hannah (1964). Eichmann in Jerusalem. $2^{a}$ ed. Nueva York: The Viking Press. Castillo, Juan Pablo (2018). «El carácter de las circunstancias del asesinato, la naturaleza del artículo 103 del Código Penal chileno y un problema civil». Revista de Ciencias Penales, Sexta Época, 45: 693-718.

24. Se han suprimido las negritas del original. 
Couso, Jaime (2019): «Artículo 292». En Jaime Couso Salas y Héctor Hernández Basualto (directores), Código Penal comentado. Parte especial. Libro segundo. Título VI (Arts. 261 a 341). Doctrina y jurisprudencia (pp. 297-326). Santiago: Thomson Reuters.

De Rivacoba y Rivacoba, Manuel (1981). Nueva crónica del crimen. Valparaíso: Edeval.

Etcheberry, Alfredo (1998a). Derecho Penal. Parte Especial. Tomo III. $3^{\text {a }}$ ed. Santiago: Jurídica de Chile.

-. (1998b). Derecho Penal. Parte Especial. Tomo II. 3. ${ }^{a}$ ed. Santiago: Jurídica de Chile.

Garrido, Mario (2010). Derecho Penal. Parte Especial. Tomo III. $4^{\text {a }}$ ed. Santiago: Jurídica de Chile.

Hernández, Héctor (2011). «Artículo 15». En Jaime Couso Salas y Héctor Hernández Basualto (directores), Código Penal comentado. Parte general. Doctrina y jurisprudencia (pp. 383-413), Santiago: Abeledo Perrot/Legal Publishing.

Mañalich, Juan Pablo (2010). Terror, pena y amnistía. El derecho penal frente al terrorismo de Estado. Santiago: Flandes indiano.

-. (2011). «Organización delictiva. Bases para su elaboración dogmática en el derecho penal chileno». Revista Chilena de Derecho, 38: 279-310. Disponible en bit. ly/3eFDYOi.

-. (2015). «El terrorismo ante el derecho penal: la propuesta legislativa del gobierno como retroceso». En Javier Couso (editor), Anuario de Derecho Público 2015 (pp. 154-171), Santiago: Universidad Diego Portales.

-. (2017). «Intervención «organizada» en el hecho punible. Esbozo de un modelo diferenciador». En Jaime Couso y Gerhard Werle (coordinadores), Intervención delictiva en contextos organizados (pp. 23-50), Valencia: Tirant lo Blanch.

-. (2018a). «La estructura típica de la asociación ilícita: el «caso Prats». SCS, 08/o7/2010, Rol núm. 2596-09». En Tatiana Vargas (directora), Casos destacados. Derecho Penal. Parte especial (pp. 303-334). Santiago: DER.

-. (2018b). «El procesamiento transicional del terrorismo de Estado a veinte años del caso Pinochet». Anales de la Universidad de Chile, 15: 75-85. Disponible en bit. ly/3g3gWSt.

Novoa, Eduardo (2005). Curso de Derecho Penal chileno. Tomo II. $3^{\text {a }}$ ed. Santiago: Jurídica de Chile.

Politoff, Sergio, Francisco Grisolía y Juan Bustos (1993). Derecho Penal Chileno. Parte Especial. $2^{\text {a }}$ ed., Santiago: Jurídica de Chile.

REYES, Ítalo (2018). «Contra la autoría mediata por dominio de la organización: Una breve aproximación desde la doctrina alemana». Revista de Estudios de la Justicia, 28: 109-141. Disponible en bit.ly/2ANiqAl.

Salazar, Manuel (2011). Las letras del horror. Tomo I: La DINA. Santiago: Lom. 


\section{Sobre el autor}

Juan Pablo Mañalich es profesor titular y director del Departamento de Ciencias Penales de la Facultad de Derecho de la Universidad de Chile. Es doctor en derecho por la Universidad de Bonn y fue becario posdoctoral de la Fundación Alexander von Humboldt. Su correo electrónico es jpmanalich@derecho.uchile.cl. 
La Revista de Estudios de la Justicia es publicada, desde 2002, dos veces al año por el Centro de Estudios de la Justicia de la Facultad de Derecho de la Universidad de Chile. Su propósito es contribuir a enriquecer el debate jurídico en el plano teórico y empírico, poniendo a disposición de la comunidad científica el trabajo desarrollado tanto por los académicos de nuestra Facultad como de otras casas de estudio nacionales y extranjeras.

\author{
DIRECTOR \\ Álvaro Castro \\ (acastro@derecho.uchile.cl) \\ SITIO WEB \\ rej.uchile.cl \\ CORREO ELECTRÓNICO \\ cej@derecho.uchile.cl \\ LICENCIA DE ESTE ARTÍCULO \\ Creative Commons Atribución Compartir Igual 4.o Internacional
}

La edición de textos, el diseño editorial

y la conversión a formatos electrónicos de este artículo

estuvieron a cargo de Tipográfica

(www.tipografica.io). 